\title{
Comparison of a New-generation Fecal Immunochemical Test (FIT) With Guaiac Fecal Occult Blood Test (gFOBT) in Detecting Colorectal Neoplasia Among Colonoscopy-referral Patients
}

\author{
DENISE PEIXOTO GUIMARÃES ${ }^{1,2,3}$, JOSE HUMBERTO FREGNANI ${ }^{1}$, RUI MANUEL REIS ${ }^{1,4,5}$, \\ LEONARDO NOGUEIRA TAVEIRA ${ }^{2}$, CRISTOVAM SCAPULATEMPO-NETO ${ }^{1,6}$, MARCUS MATSUSHITA ${ }^{6}$, \\ SANDRA REGINA MORINI SILVA ${ }^{6}$, CEYTON ZANARDO OLIVEIRA ${ }^{7 *}$, ADHEMAR LONGATTO-FILHO ${ }^{1,3,4}$, \\ CARITA EKLUND $^{8}$, LEA PALOHEIMO $^{8}$, EDMUNDO MAUAD $^{3}$, OSMO SUOVANIEMI $^{8,9}$ and KARI SYRJÄNEN ${ }^{1,9}$ \\ ${ }^{1}$ Molecular Oncology Research Center, ${ }^{2}$ Department of Endoscopy, ${ }^{3}$ Cancer Prevention Department, \\ ${ }^{4}$ Life and Health Sciences Research Institute (ICVS), \\ School of Health Sciences, University of Minho, Braga, Portugal; \\ ${ }^{5}$ ICVS/3B's - PT Government Associate Laboratory, Braga/Guimarães, Portugal; \\ ${ }^{6}$ Department of Pathology, ${ }^{7}$ Department of Biostatistics, Barretos Cancer Hospital, Barretos, Brazil; \\ ${ }^{8}$ Department of Research and Development, ${ }^{9}$ Department of Clinical Research, Biohit Oyj, Helsinki, Finland
}

\begin{abstract}
Background/Aim: The aim of the present study was to compare fecal immunochemical tests (FITs) for colorectal cancer (CRC) screening with the traditional guaiac-based FOB tests (gFOBT). Materials and Methods: A cohort of 368 colonoscopy-referral patients were evaluated by $i)$ the new-generation FIT: ColonView quick test (CV; Biohit Oyj, Finland) and ii) a conventional gFOBT HemoccultSENSA (HS; Beckman Coulter, USA). Three fecal samples were requested for both assays, and all subjects underwent diagnostic colonoscopy with biopsy confirmation. Sensitivity ( $S E)$, specificity $(S P)$, positive predictive value $(P P V)$, negative predictive value (NPV) and area under curve $(A U C)$ were calculated for both tests using three endpoints: adenoma (A), advanced adenoma (AA) and adenocarcinoma $(A C)$. Results: Colonoscopy and biopsies disclosed normal mucosa in 90/378 (24.5\%) subjects, early A in 108/368 (29.3\%) cases, $A A$ in $48 / 368$ (13.0\%) and $A C$ in $37 / 368$
\end{abstract}

This article is freely accessible online.

*Current affiliation: Education and Research, BP - A Beneficência Portuguesa de São Paulo, São Paulo, Brazil.

Correspondence to: Kari Syrjänen, MD, Ph.D., FIAC, Department of Clinical Research, Biohit Oyj, Laippatie 1, 00880, Helsinki, Finland, e-mail: kari.syrjanen@biohit.fi

Key Words: Colorectal cancer, screening, fecal occult blood (FOB), guaiac-based FOB test (gFOBT), fecal immunochemical test (FIT), performance, colonoscopy.
(10.1\%), and non-neoplastic conditions in the remaining 85 (30.3\%). For the AC endpoint, the $\mathrm{CV}(\mathrm{Hb} / \mathrm{Hp})$ test had 94.6\% SE and $65.1 \%$ SP (AUC=0.799), while the HS test had $S E$ of $75.7 \%$ and SP of $84.3 \%(A U C=0.800)$. For the $A$ endpoint, the difference between $C V$ and $H S$ was even more pronounced; SE of $44.2 \%$ and $19.2 \%$, respectively $(p<0.0001) . \mathrm{Hb}$ and $\mathrm{Hb} / \mathrm{Hp}$ complex of the CV test showed equal performance for all endpoints. Conclusion: Sensitivity (94.6\%) of the ColonView quick test for the most reproducible endpoint (invasive CRC) far exceeded the pooled sensitivity (79\%) estimated in a recent meta-analysis for 8 common FIT brands. As shown in a previous study, ColonView quick test is superior in SE to HemoccultSENSA test, making $C V$ a perfect FIT for organized CRC screening.

Colorectal cancer (CRC) is the third most common malignancy, with over 1.3 million new cases and over 600.000 annual deaths worldwide in 2012 (1). In Brazil, the incidence of $\mathrm{CRC}$ remains lower than in many high-income countries, but mortality is similar, reflecting an incidence-tomortality ratio disparity in Brazil (2-4).

CRC is readily suitable for organized screening, offering a possibility for both early detection and cancer prevention, with reduced mortality rates $(5,6)$. The majority of CRC develops from precursor lesions, i.e., adenoma, and several studies have estimated the accuracy of screening methods also for advanced adenomas. Effective CRC screening can achieve both the primary and secondary prevention, by detecting cancer precursors (polyps, adenomas) and early cancers, respectively $(7,8)$. 
Common CRC screening tests include FOBT (fecal occult blood test), FS (flexible sigmoidoscopy), and colonoscopy $(9,10)$. FOBT has been the most commonly used test in several organized, population-based programs (11-13), and randomized trials indicate that screening by FOBT can reduce CRC mortality by $15-33 \%$ (14-16). Two main types of FOBT exist on the market: guaiac-based test (gFOBT) and immunochemical test (FIT). The former is based on the oxidation of guaiac by hydrogen peroxidase, reacts with any peroxidase in the feces, is not specific for human hemoglobin $(\mathrm{Hb})(17)$, is affected by several foodstuffs (with any peroxidase content), medications and certain chemicals.

Since the invention of the immunochemical test principle by the founder of Biohit Oyj, Suovaniemi et al. (18), the FITs were developed to circumvent these problems of the guaiac tests, using an antibody specific to human hemoglobin (19). Compared with the gFOBTs, FITs show a superior sensitivity (SE) and specificity (SP) in CRC screening (20).

In the only randomized control trial published so far, the performance of FITs was clearly superior to gFOBTs in detecting any type of colorectal neoplasia (21). In a recent meta-analysis including 8 commercial FIT brands, the pooled SE and SP for the cancer endpoint were $79 \%$ and $94 \%$, respectively, with relatively small variation between the different FIT brands (22). One of the new-generation FITs, not included in this meta-analysis (22), was recently launched by Biohit Oyj (Helsinki, Finland), with the proprietary name ColonView Quick Test. This immunochromatographic test (18, 19) was designed for quick and qualitative detection of human $\mathrm{Hb}$ and $\mathrm{Hb} / \mathrm{Hp}$ complex in the fecal samples, and visual and/or automated reading of the results.

Performance of ColonView quick test was recently compared head-to-head with HemoccultSENSA in the detection of colorectal neoplasia among colonoscopy-referral patients (23). For all study endpoints (adenoma, adenocarcinoma, adenoma \& carcinoma), the ColonView quick test was up to $60 \%$ more sensitive, but $15-20 \%$ less specific than HemoccultSENSA (23). To validate these exceptional results of Vasilyev et al., (23) in another (very different) population, the present study was designed to compare the ColonView quick test with the market-leader gFOBT (HemoccultSENSA) in detection of colorectal neoplasia among colonoscopy-referral patients at the Barretos Cancer Hospital (Barretos-SP, Brazil).

\section{Materials and Methods}

Study design and eligibility criteria. This trial was conducted at Barretos Cancer Hospital (BCH) (Barretos-SP, Brazil), in collaboration with Biohit Oyj (Helsinki, Finland). Consecutive patients (with no age limit), attending the Outpatient Department of Endoscopy for an appointment to colonoscopy were enrolled in the study.

Potentially eligible subjects were identified among the outpatient clinic patients referred for colonoscopy with different indications.
Table I. Key demographic and clinical features of the study subjects.

\begin{tabular}{lcc}
\hline Features & Number $(\mathrm{n}=368)$ & $\% 1$ \\
\hline Mean age at enrollment $( \pm$ SD, range) & $53.3(13.7,18-88)$ & NA \\
Gender & 226 & 61.4 \\
Female & 142 & 38.6 \\
Male & & \\
Family history of colorectal cancer & 234 & 63.9 \\
No & 132 & 36.1 \\
Yes & 2 & \\
Missing data & 289 & \\
FAP patients & 46 & 13.7 \\
No & 33 & \\
Yes & & \\
Missing data & & \\
Colonoscopic findings & 133 & 36.3 \\
Diverticula & 233 & 63.7 \\
No & & \\
Yes & 331 & 90.2 \\
Hemorrhoids & 36 & 9.8 \\
No & & \\
Yes &
\end{tabular}

${ }^{1}$ Percentages were calculated after excluding participants with missing data.

Every patient was asked to read the patient information sheet, and consent to the study by signing a written participation consent. Patients consenting to participate were given a box containing all necessary materials of both FOB tests for sampling, as well as instructions for sample collection, handling and delivering to the test laboratory analysis at the day of colonoscopy. All colonoscopies were performed at the Department of Endoscopy at $\mathrm{BCH}$. This study was approved by the Institutional Review Board of the $\mathrm{BCH}$.

Eligible patients were all adult women and men, irrespective whether symptomatic or asymptomatic, scheduled for diagnostic colonoscopy and who gave a written consent to participate. The following patients were considered ineligible: 1) patients who refused to participate; 2) patients whose colonoscopic examination remained unsatisfactory (judged by the endoscopist); 3) patients who had previous colon surgery; 4) patients who presented with visible blood in the stools regularly or frequently ( $>1$ episode per week); 5) patients who had documented inflammatory bowel disease (IBD), known radiation proctitis; 6) patients who failed to return at least one adequate stool sample for both FOB tests.

Sample collection. Being a new-generation FIT, ColonView ${ }^{\circledR}$ quick test (subsequently CV) (Biohit Oyj, Helsinki) (19) does not necessitate any preparatory steps of the patient or compliance with any restrictions in the daily diet or medication. Hemoccult ${ }^{\circledR}$ SENSA ${ }^{\circledR}$ (subsequently HS) (Beckman Coulter Inc., Passadena) in contrast is a gFOBT that necessitates compliance with certain restrictions in the daily diet and medication. To make the comparison of these two basically different tests as unbiased as possible, the Delivery Box contained detailed instructions for the patient preparation as well as precautions in diet and daily medication. Accordingly, the subjects were instructed to avoid non-steroidal anti-inflammatory drugs (more than one adult aspirin a day) for 7 days before and during the stool collection period as well as to avoid vitamin $\mathrm{C}$ in 


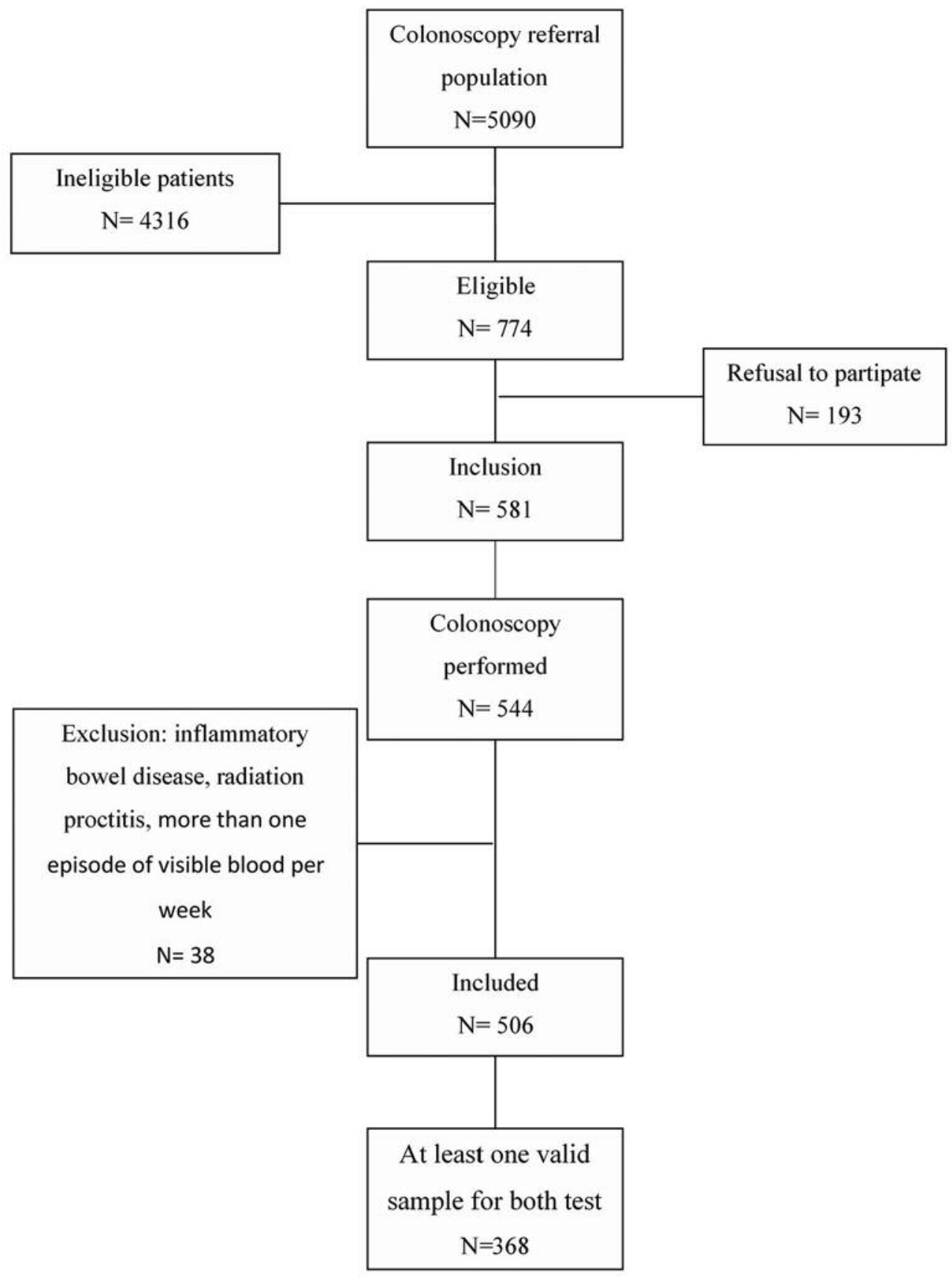

Figure 1. Flowchart of the patient enrolment in the study.

excess of $250 \mathrm{mg}$ a day from supplements, and citrus fruits and juices for three days before and during the stool collection period. Further restrictions included avoidance of red meats (beef, lamb, liver) during the same period.

For both tests, the subjects were instructed to collect 3 fecal samples on 3 consecutive days. For the HS test, the collected samples were smeared onto the test card area, and for the CV test, the samples were collected into 3 separate tubes, following the manufacturers' instructions. Test cards and tubes were returned to
$\mathrm{BCH}$ laboratory at the day of colonoscopy and processed on the very same day.

Sample processing and interpretation of the results. Due to the basically different principles of the CV quick test and HS test, also the sample processing in the laboratory is different. For the HS testing only $\mathrm{Hb}$, the result is interpreted by visual reading as positive or negative. The analytical sensitivity of HS is reported to be $0.3 \mathrm{mg} \mathrm{Hb} / \mathrm{g}$ feces (23). 
Because $\mathrm{CV}$ quick test consists of two components ( $\mathrm{Hb}$ and $\mathrm{Hb} / \mathrm{Hp}$ complex), the test result has four options: both components negative, both components positive, either $\mathrm{Hb}$ or $\mathrm{Hb} / \mathrm{Hp}$ complex positive. The results are interpreted both by visual reading (VR) and by automatic reading (AR), using opTrilyzer Lateral flow reader (opTricon GmbH, Berlin, Germany), as described before (23).

In fully compliant patients, 3 stool samples were tested by both $\mathrm{CV}$ and HS test, and the result was interpreted positive if any of the 3 samples tested positive. For $\mathrm{CV}$, any sample positive for either $\mathrm{Hb}$ or $\mathrm{Hb} / \mathrm{Hp}$ complex was classified as a positive test. The analytical sensitivity for $\mathrm{CV} \mathrm{Hb}$ is $15 \mathrm{ng} / \mathrm{ml}$, and for $\mathrm{CV} \mathrm{Hb} / \mathrm{Hp}$ complex, $4 \mathrm{ng} / \mathrm{ml}(23)$.

Colonoscopy procedure and lesions. All patients who returned at least one adequate sample for both CV and HS tests were subjected to colonoscopy, providing the histological confirmation to be used as the gold standard in calculating the performance indicators of the two tests. In the case of completely normal colonoscopy, however, biopsies were not taken, and in such a case, normal colonoscopy was used as the gold standard indicating a negative result regarding the study endpoints.

All colonoscopies were performed by experienced endoscopists with high-definition colonoscope (Olympus GIF 180; Tokyo, Japan), using a targeted dye spraying of the colon with $0.4 \%$ indigo carmine solution. Detailed description of all detected lesions was provided, including their number, size and exact locations: proximal (from cecum to splenic flexure) or distal (descending colon to rectum). Superficial lesions were characterized according to Paris classification: type 0-I, polypoid (0-Is, sessile; 0-Isp, semipedunculated; 0-Ip, pedunculated); type 0 -II, non-polypoid (0-IIa, slightly elevated; 0-IIb, flat; 0-IIc, slightly depressed); type 0-III, excavated; LST, laterally spreading type (24). All detected lesions were removed, if possible, or underwent biopsy. Histological analysis was performed by experienced pathologists using the latest WHO criteria (25). Criteria of advanced adenoma (AA) included an adenoma: i) of at least $10 \mathrm{~mm}$ in diameter, ii) with at least $25 \%$ of villous architecture, iii) with high-grade dysplasia or iv) with an early invasive cancer. If more than one lesion was present, the patient was classified by the most advanced lesion, in the descending order of severity: AC (Adenocarcinoma), AA, early A (adenoma).

In all statistical analyses, the patients with diverticula, hemorrhoids, or hyperplastic polyps were classified as having normal (non-neoplastic) findings.

Ethics approval and consent to participate. This study was approved by the Institutional Review Board of the $\mathrm{BCH}$ (Registration number 753/2013). Every patient consented to the study by signing a written consent to participate.

Statistical analysis. All statistical analyses were performed using the SPSS 20.0.0.1 for Windows (IBM, NY, USA). The descriptive statistics were conducted according to routine procedures. Performance indicators (SE; sensitivity, SP; specificity, PPV; positive predictive value, NPV; negative predictive value, and their 95\% CI) and the area under ROC (Receiver Operating Characteristics) called AUC, of the two tests were calculated separately for each study endpoint. Because the CV test consists of two components, these performance indicators were calculated
Table II. Distribution of the colonoscopy findings of the patients.

\begin{tabular}{lrr}
\hline Histological type of colorectal lesions & N & $\%$ \\
\hline Normal mucosa & 90 & 24.5 \\
Non-neoplastic lesions (e.g. colitis) & 35 & 9.5 \\
Hyperplastic polyp & 47 & 12.8 \\
Sessile serrated adenoma & 3 & 0.8 \\
Early Adenoma & 108 & 29.3 \\
Advanced Adenoma & 48 & 13.0 \\
Carcinoma & 37 & 10.1 \\
Total & 368 & 100 \\
\hline
\end{tabular}

\#The most severe lesion was listed in patients with more than one type of disease.

separately for $\mathrm{Hb}$ and $\mathrm{Hb} / \mathrm{Hp}$ complex. Significance of the difference between AUC values was estimated using the McNemar test with $95 \% \mathrm{CI}$.

\section{Results}

Between January 2014 and December 2016, a total of 5090 consecutive patients were screened for eligibility, and 774 tentatively meeting the eligibility criteria were invited to the clinic (Figure 1). Of those, 581/774 (75.1\%) agreed to participate and signed the consent form. Thirty eight of these 581 patients, however, had to be excluded due to the presence of radiation proctitis, IBD or more than one episode/week of visible fecal blood. At the end, a total of 368 patients provided at least one adequate sample for both tests, underwent colonoscopy and were included in the final study cohort (Figure 1).

The demographic and clinical features of the 368 patients included in the study are summarized in Table I. The patients were predominantly women $(61.4 \%)$, with the mean age $( \pm \mathrm{SD})$ of $53.3 \pm 13.9$ years (range:18-88 years). Altogether, $132(36.1 \%)$ patients reported a family history of CRC and $46(13.7 \%)$ were patients with a history of familiar adenomatous polyposis (FAP). On colonoscopy, 90/368 (24.4\%) patients had completely normal mucosa. Hyperplastic polyps were detected in 125 patients, sessile serrated adenoma in 17 , adenoma (A) in 175, advanced adenoma (AA) in 48 patients, while 37 patients had an adenocarcinoma (AC). Altogether, 185/368 (66.5\%) patients presented with more than just one lesion.

Colonoscopy and histological examination of the biopsies confirmed early A as the most severe lesion in 108 (29.3\%) cases, AA in $48(13.0 \%)$ and $\mathrm{AC}$ in $37(10.1 \%)$. The remaining $85(30.3 \%)$ subjects had serrated lesions (hyperplastic polyps or serrated sessile polyp) or benign nonneoplastic lesions (e.g. IBD, colitis) (Table II).

Of the 368 patients, 120 (32.6\%) were positive for the HS (HemoccultSENSA) test, 164 (44.6\%) for the CV Hb test 
Guimarães et al: FIT and gFOBT as Screening Tools of Colorectal Neoplasia

Table III. Performance indicators of the ColonView and HemoccultSENSA test for the carcinoma (AC) endpoint.

\begin{tabular}{|c|c|c|c|c|c|c|c|c|c|c|c|c|}
\hline & \multicolumn{2}{|c|}{ Carcinoma } & \multicolumn{2}{|c|}{ Sensitivity } & \multicolumn{2}{|c|}{ Specificity } & \multicolumn{2}{|r|}{ PPV } & \multicolumn{2}{|r|}{ NPV } & \multicolumn{2}{|c|}{ AUC $(95 \% \mathrm{CI})$} \\
\hline & Yes & No & $\%$ & $95 \% \mathrm{CI}$ & $\%$ & $95 \% \mathrm{CI}$ & $\%$ & $95 \% \mathrm{CI}$ & $\%$ & $95 \% \mathrm{CI}$ & & \\
\hline \multicolumn{13}{|c|}{ Stool test } \\
\hline \multicolumn{13}{|c|}{ HemoccultSENSA } \\
\hline Positive & 28 & 27 & 75.7 & 58.8 to 88.2 & 84.3 & 78.0 to 89.4 & 50.9 & 41.2 to 60.5 & 94.2 & $90.1 \%$ to 96.6 & 0.800 & 0.713 to 0.886 \\
\hline Negative & 9 & 145 & & & & & & & & & & \\
\hline \multicolumn{13}{|c|}{ ColonView Hb VR } \\
\hline Positive & 34 & 61 & 91.9 & 78.1 to 98.3 & 64.5 & 56.9 to 71.7 & 35.8 & 30.8 to 41.1 & 97.4 & 92.6 to 99.1 & 0.782 & 0.711 to 0.854 \\
\hline Negative & 3 & 111 & & & & & & & & & & \\
\hline \multicolumn{13}{|c|}{ ColonView $\mathrm{Hb} / \mathrm{Hp}$ VR } \\
\hline Positive & 34 & 66 & 91.9 & 78.1 to 98.3 & 61.6 & 53.9 to 68.4 & 34.0 & 29.4 to 38.9 & 97.2 & 92.2 to 99.1 & 0.768 & 0.695 to 0.841 \\
\hline Negative & 3 & 106 & & & & & & & & & & \\
\hline \multicolumn{13}{|c|}{ ColonView Hb AR } \\
\hline Positive & 34 & 55 & 91.9 & 78.1 to 98.3 & 68.0 & 60.5 to 74.9 & 38.2 & 32.8 to 44.0 & 97.5 & 92.9 to 99.1 & 0.800 & 0.730 to 0.869 \\
\hline Negative & 3 & 117 & & & & & & & & & & \\
\hline \multicolumn{13}{|c|}{ ColonView Hb/Hp AR } \\
\hline Positive & 35 & 60 & 94.6 & 81.8 to 99.3 & 65.1 & 57.5 to 72.2 & 36.8 & 31.9 to 42.1 & 98.2 & 93.5 to 99.5 & 0.799 & 0.732 to 0.865 \\
\hline Negative & 2 & 112 & & & & & & & & & & \\
\hline
\end{tabular}

AR: Automatic reading; VR: visual reading; PPV: positive predictive value; NPV: negative predictive value; AUC: area under the curve.

Table IV. Performance indicators of the ColonView and HemoccultSENSA test for adenoma (A) and advanced adenoma (AA) endpoints.

\begin{tabular}{|c|c|c|c|c|c|c|c|c|c|c|}
\hline & \multicolumn{2}{|c|}{ Sensitivity } & \multicolumn{2}{|c|}{ Specificity } & \multicolumn{2}{|c|}{ PPV } & \multicolumn{2}{|r|}{ NPV } & \multicolumn{2}{|c|}{ AUC $(95 \% \mathrm{CI})$} \\
\hline & $\%$ & $95 \% \mathrm{CI}$ & $\%$ & $95 \% \mathrm{CI}$ & $\%$ & $95 \% \mathrm{CI}$ & $\%$ & $95 \% \mathrm{CI}$ & & \\
\hline \multicolumn{11}{|l|}{ HemoccultSENSA } \\
\hline Adenoma & 19.2 & 13.47 to 26.3 & 84.3 & 78.0 to 89.4 & 52.6 & 40.9 to 64.1 & 53.5 & 51.0 to 56.0 & 0.518 & 0.455 to 0.580 \\
\hline Advanced adenoma & 29.2 & 17.0 to 44.1 & 84.3 & 78.0 to 89.4 & 34.2 & 22.8 to 47.6 & 81.0 & 51.0 to 56.0 & 0.518 & 0.455 to 0.580 \\
\hline \multicolumn{11}{|l|}{ ColonView Hb VR } \\
\hline Adenoma & 44.2 & 36.3 to 52.4 & 64.5 & 56.49 to 71.7 & 53.1 & 46.4 to 59.7 & 56.1 & 51.6 to 60.4 & 0.544 & 0.481 to 0.606 \\
\hline Advanced adenoma & 64.6 & 49.5 to 77.8 & 64.5 & 56.9 to 71.7 & 53.4 & 27.5 to 40.5 & 77.9 & 81.4 to 90.7 & 0.646 & 0.557 to 0.734 \\
\hline \multicolumn{11}{|l|}{ ColonView Hb/Hp VR } \\
\hline Adenoma & 41.7 & 33.8 to 49.8 & 61.6 & 53.9 to 68.9 & 49.6 & 43.0 to 56.2 & 53.8 & 49.4 to 58.2 & 0.516 & 0.454 to 0.579 \\
\hline Advanced adenoma & 52.1 & 37.1 to 66.7 & 61.6 & 53.9 to 68.9 & 27.5 & 21.4 to 34.5 & 82.2 & 77.0 to 86.4 & 0.569 & 0.476 to 0.661 \\
\hline
\end{tabular}

VR: Visual reading; PPV: positive predictive value; NPV: negative predictive value; AUC: area under the curve.

and $165(44.8 \%)$ for the $\mathrm{CV} \mathrm{Hb} / \mathrm{Hp}$ complex test. Performance indicators of the two tests for the AC endpoint are shown in Table III. SE of the CV test for the AC endpoint was ranging from $91.9 \%$ to $94.6 \%$, and SP from $61.6 \%$ to $68.0 \%$, depending on the marker $(\mathrm{Hb}$ or $\mathrm{Hb} / \mathrm{Hp})$ and the test reading (AR or VR). The $\mathrm{CV} \mathrm{Hb/Hp} \mathrm{test} \mathrm{in} \mathrm{the}$ AR mode had the highest SE for AC $(94.6 \%$; $95 \% \mathrm{CI}=81.8$ 99.3) whereas the $\mathrm{CV} \mathrm{Hb}$ test in the $\mathrm{AR}$ mode had the highest SP (68.0\%; 95\%CI=60.5-74.9) (Table III).

The HS test had the lowest SE for AC (75.7\%; 95\%CI=58.888.2), but the highest SP (84.3\%; 95\% CI=78.0-89.4). The CV $\mathrm{Hb}$ and $\mathrm{Hb} / \mathrm{Hp}$ complex test showed similar results in both VR and $\mathrm{AR}$ reading modes, with the highest $\mathrm{SE}$ established for the $\mathrm{Hb} / \mathrm{Hp}$ complex in the AR mode (Table III). Differences between $\mathrm{HS}$ test and $\mathrm{CV} \mathrm{Hb} \mathrm{VR,} \mathrm{Hb/Hp} \mathrm{VR,} \mathrm{Hb} \mathrm{AR} \mathrm{and}$ $\mathrm{Hb} / \mathrm{Hp} \mathrm{AR}$ were statistically significant for both $\mathrm{SE}(p=0.031$; $p=0.031 ; p=0.031$ and $p=0.016$, respectively) and SP $(p<0.001 ; p<0.0001 ; p<0.0001$ and $p<0.0001$, respectively).

For the A and AA, the difference in performance between the CV and HS was even more pronounced (Table IV). The SE of HS for the A endpoint was only $19.2 \%(95 \% \mathrm{CI}=13.5-$ $26.3)$ as compared with $44.2 \%(95 \% \mathrm{CI}=36.3-52.4)$ for the CV Hb VR $(p<0.0001)$ and $41.7 \%(95 \% \mathrm{CI}=33.8-49.8)$ for the $\mathrm{CV} \mathrm{Hb/Hp} \mathrm{VR}(p<0.0001)$ (Table IV). For the AA endpoint, 
the $\mathrm{CV} \mathrm{Hb}$ and $\mathrm{Hb} / \mathrm{Hp}$ in both $\mathrm{VR}$ and $\mathrm{AR}$ mode were also clearly superior in SE to the HS test $(p<0.0001 ; p=0.001$; $p=0.001 ; p=0.003)$. The same was true for the $\mathrm{A}+\mathrm{AC}$ endpoint $(p<0.0001 ; p<0.0001 ; p<0.0001 ; p<0.0001)$.

There was no difference in SE between the $\mathrm{CV} \mathrm{Hb}$ and $\mathrm{Hb} / \mathrm{Hp}$ complex for the A $(44.2 \%$ vs. $41.7 \%)$, AA $(67.4 \% v s$. $52.1 \%)$, or AC (91.9\% vs. 91.9\%) endpoints, respectively.

\section{Discussion}

During the past decades, different guaiac-based FOBTs (gFOBT) have become very popular screening tools for CRC in many countries (11). However, their use is hampered by several shortcomings, including non-specificity to human blood, false-positive reactions to non-specific peroxidases in the diet, as well as complicated dietary restrictions, leading to poor test compliance among the test subjects (23). Associated with poor sensitivity and specificity, the gFOBTs have become obsolete and have been progressively replaced by the FITs in population-based CRC screening programs $(20,26)$. In parallel, an increasing number of studies have compared FIT and gFOBTs (27). Despite some inconsistent results, these data suggest that the sensitivity of the FIT assays is substantially better than that of the gFOBTs $(23$, 28-33). This was also confirmed in the only randomized controlled trial reported so far, indicating that the performance of FIT tests is clearly superior to gFOBT in detecting any type of colorectal neoplasia (21).

The invention of the immunochemical test principle by the founder of Biohit Oyj, Suovaniemi et al., $(18,34)$, has led to rapid emergence of a large number of commercial FIT brands to the market. The accumulated literature on FIT tests was recently subjected to a meta-analysis by Lee et al. (22). After careful selection, the authors found 18 of the 53 available studies eligible for their formal meta-analysis (22). This study covered 8 different commercial FIT brands, but the Biohit ColonView quick test was not included, because it was not yet on the market $(22,23)$. Worth noticing in this meta-analysis is the fact that the authors only used the CRC (invasive cancer) endpoint while pooling the FIT results (22). This decision was based on their observation that only a subset of all studies reported data on adenomatous polyps (A, AA) and that there was a wide variability in definitions of polyps (22). Thus, all studies reporting test performance estimates for detection of adenomas and advanced adenomas only, were excluded from their analysis.

In this meta-analysis of 8 FIT brands, the pooled SE and SP for the CRC endpoint were: $79 \%(95 \% \mathrm{CI}=69-86)$ and 94\% (CI=92-95), respectively, with an overall diagnostic accuracy of $95 \%(\mathrm{CI}=93-97)(22)$. There is no doubt that the Biohit ColonView quick test favourably competes with and even exceeds these pooled sensitivity indicators of the 8 FIT brands (22), as clearly demonstrated by the first head-to-head comparison of the $\mathrm{CV}$ and $\mathrm{HS}$ tests, conducted in St. Petersburg (Russia) (23). In this $100 \%$ biopsy-confirmed colonoscopy-referral setting of 300 patients, the CV test was superior in performance to the HS test for the A- and combined A+AC endpoints (23). This difference was most marked in detection of the proximal neoplasia, of which almost $60 \%$ were missed by the HS test, and none $(100 \%$ detection), by the $\mathrm{CV} \mathrm{Hb/Hp} \mathrm{complex} \mathrm{(23).} \mathrm{As} \mathrm{compared}$ with the meta-analytical data of Lee et al. (22), the CV test showed $100 \% \mathrm{SE}$ and $95.3 \% \mathrm{SP}(\mathrm{AUC}=0.977)$ for the proximal colon neoplasia and $98.2 \% \mathrm{SE}$ and $95.3 \% \mathrm{SP}$ (AUC $=0.968$ ) for the distal neoplasia (23).

These exceptional performance indicators of the CV test reported in the previous study (23) advocate the prompt adoption of this new FIT assay for CRC screening. To proceed with that, it is important, however, to validate the results also in different populations, which was done in the present study using a similar design (head-to-head comparison of the $\mathrm{CV}$ and $\mathrm{HS}$ tests) in colonoscopy-referral patients at a leading cancer hospital in Brazil (BCH). All compliant patients $(n=368)$ provided at least one fecal sample for both tests and underwent diagnostic colonoscopy with directed biopsies used as the gold standard test, as in the first study (23).

The results of the present study clearly confirm the observations of the comparison St. Petersburg study (23). Accordingly, of the two tests, CV was clearly the most sensitive test, resulting in a higher SE for all endpoints (A, AA, $A C, A+A C)$ used in this study. The same was true for both the visual (VR) and automatic reading (AR) of the $\mathrm{CV} \mathrm{Hb}$ and $\mathrm{CV}$ $\mathrm{Hb} / \mathrm{Hp}$ tests (Tables III \& IV). For the AC endpoint, the SE of $\mathrm{CV}$ reached $94.6 \%$, in contrast to that of the HS test levelling off at $75.7 \%$. Undoubtedly, this must be considered as the single most important discovery of the present study (Table III). As pointed out by Lee et al., in their meta-analysis (22), the invasive $\mathrm{CRC}$ (AC in the present study) was the only possible endpoint that could be used for reliable estimation of the pooled SE and SP of the 8 commercially available FIT brands (22). The argument was that adenomas were only reported in a minor subset of the published studies, and, furthermore, their reporting and classification was not reproducible and far too heterogenic to be used as the study endpoints for the pooled estimates in meta-analysis.

Notwithstanding the above, we wanted to reproduce the St. Petersburg study (23), by testing also the other endpoints, including $\mathrm{A}, \mathrm{AA}$ and $\mathrm{A}+\mathrm{AC}$. Even if the test performance indicators of the $\mathrm{CV}$ test for adenomas did not reach the exceptionally high levels reported in the first study (23), the results of these two studies are concordant. This is because the indicators of the HS test remained also far below the values reached in the first study (23). In the present setting, the SE of the CV test for the AA endpoint was $35.2 \%$ higher than the SE of the HS test (Table IV). The same holds true 
also for the A endpoint, where the $\mathrm{CV}$ Hb test showed SE of $44.2 \%$ as compared to only $19.2 \%$ by the HS test.

These differences in SE between the two tests even exceed those observed in the previous study (23). The observed variance in the absolute performance indicators between the present study and the St. Petersburg study (23) are explained by several factors, most likely ascribed to different patient population and their distinct clinical features. This includes the spectrum of clinical conditions detected in the two cohorts (Table II). It should be also emphasized that most patients in the present cohort are oncological high-risk patients, including those with family history of CRC and FAP (Table I). Furthermore, one cannot exclude the possibility that the adenoma lesions were classified differently in the two studies, which is a common shortcoming shared by the FIT studies, as emphasized by Lee et al. (22).

Although not including the CV test, there are some studies where the HS test has been compared with another FIT brands on the market. Smith et al. (35) conducted a pairwise comparison of Hemoccult II Sensa with a brush-sampling FIT (InSure, Enterix) in a screening cohort and in a diagnostic group of symptomatic patients. The sensitivity of HS-II in the screening cases was $75 \%$ for CRC, but only $27 \%$ for AAs (35). Results in alignment with those recently reported by Parra-Blanco et al. (36), who evaluated another FIT brand (OC-LightTM, Eiken Chemical Co., Ltd., Japan) with gFOBT brand (non-rehydrated G-FOBT, HemofecTM, Roche Diagnostics S.L., Barcelona, Spain) in a screening population. For FIT test, they showed SE of $56.8 \%$ (95\% CI=41.8-70.7) for AA, which was up to 3-times higher than the SE of the gFOBT (36). The results of both of these studies are in full agreement with our experience on the head-to-head comparison of the CV and HS tests. Both our studies indicated that test specificity is somewhat higher for the HS than the CV test, albeit the figures were different in Barretos and St. Petersburg ((23), Table IV). One of the limitations of this study is the fact that a highly selected population undergoing colonoscopy for several 'high-risk' indications was investigated. Therefore, care should be taken when applying our results to an average-risk, asymptomatic population.

The Hb molecule consists of 2 pairs of peptide chains ( $\alpha$ and $\beta$-globins) and 4 heme groups, each with one atom of iron. Free $\mathrm{Hb}$ may be separated into $\alpha-\beta$ molecules, which are bound to a protein called haptoglobin (5). $\mathrm{Hb} / \mathrm{Hp}$ complex plays an important role in the retrieval of $\mathrm{Hb}$ from lysed erythrocytes and is relatively stable against acid and proteolytic degradation. In practical terms, this suggests that the $\mathrm{Hb} / \mathrm{Hp}$ complex can be detected even after a longer passage through the bowel, increasing the chance of detection by the $\mathrm{Hb} / \mathrm{Hp}$ complex of FOB derived from the lesions in the proximal colon $(23,28)$.
Like in the previous study (23), this was also examined in the present study by investigating the capacity of both $\mathrm{CV}$ and HS in detecting proximal and distal AC or AA. The SE of the CV test for distal $\mathrm{AC}$ was $100 \%(95 \% \mathrm{CI}=88.4-100)$ for both $\mathrm{CV} \mathrm{Hb}$ and $\mathrm{Hb} / \mathrm{Hp}$, and the $\mathrm{SP}$ was ranging from $61.6 \%$ to $68.0 \%$, respectively. For the HS test, SE and SP were $83.3 \%$ and $84.3 \%$, respectively. For proximal AC, the SE of the HS test $(56.8 \%)$ was lower than that for the distal AC (68.8\%), and far inferior to that of the CV test $(81.3 \%-87.5 \%)$ (data not in Results). Albeit confirming the previous data (23), there were differences in the absolute indicator values between the two studies. The difference between $\mathrm{Hb}$ and $\mathrm{Hb} / \mathrm{Hp}$ complex indicators was also assessed for all endpoints, irrespective of the location of the neoplasia. This was prompted by our previous observations (23) and those of others (28) confirming that detection of the $\mathrm{Hb} / \mathrm{Hp}$ complex displays a significantly increased SE for all colorectal neoplasms as compared to $\mathrm{Hb}$ detection alone. However, in the present study, we failed to find a marked difference between $\mathrm{Hb}$ and $\mathrm{Hb} / \mathrm{Hp}$ complex for any of the study endpoints, which is in contrast to our previous observations (23). The reasons for this discrepancy remain unexplained.

Taken together, the head-to-head comparison of the newgeneration FIT test (ColonView quick test) with the marketleading conventional gFOBT (HemoccultSENSA), confirmed the superiority of the FIT test. Although evident for all adenoma endpoints as well, most importantly, this difference in the sensitivity between CV- and HS tests was significant for the currently accepted most reliable study endpoint (invasive CRC) (22). This CRC endpoint was used in the most recent meta-analysis of the common FIT brands because the adenoma endpoints reported in the literature were considered highly variable and non-reproducible. Sensitivity (94.6\%) of the ColonView quick test for the CRC endpoint far exceeds the pooled sensitivity $(79 \%)$ calculated in a meta-analysis (22) for the 8 common FIT brands on the market.

\section{Conclusion}

Supported by the previously reported excellent results also for the adenoma endpoints (23), the present data indicate that ColonView quick test is a perfect FIT for CRC screening.

\section{Conflicts of Interest}

Kari Syrjänen is the Chief Medical Director, Biohit Oyj; Osmo Suovaniemi is the Chairman of the Board, Biohit Oyj; Carita Eklund and Lea Paloheimo are employees of Biohit Oyj.

\section{Acknowledgements}

The Authors thank Ms. Gabriela de Oliveira for the identification and tracking all the patients included in the study. The Authors would also like to give special thanks to Ms. Thais Thalarico for 
assisting in data analysis, as well as to Ms. Maraisa Costa and Ms. Adriana Carloni for running the analysis of the gFOBT and FIT tests. This study was supported by Biohit Oyj.

\section{References}

1 Ferlay J, Soerjomataram I, Dikshit R, Eser S, Mathers C, Rebelo M, Parkin DM, Forman D and Bray F: Cancer incidence and mortality worldwide: sources, methods and major patterns in GLOBOCAN 2012. Int J Cancer 136(5): E359-386, 2015.

2 Sunkara V and Hebert JR: The colorectal cancer mortality-toincidence ratio as an indicator of global cancer screening and care. Cancer 121(10): 1563-1569, 2015.

3 Goss PE, Lee BL, Badovinac-Crnjevic T, Strasser-Weippl K, Chavarri-Guerra Y, St Louis J, Villarreal-Garza C, Unger-Saldana K, Ferreyra M, Debiasi M, Liedke PE, Touya D, Werutsky G, Higgins M, Fan L, Vasconcelos C, Cazap E, Vallejos C, Mohar A, Knaul F, Arreola H, Batura R, Luciani S, Sullivan R, Finkelstein D, Simon S, Barrios C, Kightlinger R, Gelrud A, Bychkovsky V, Lopes G, Stefani S, Blaya M, Souza FH, Santos FS, Kaemmerer A, de Azambuja E, Zorilla AF, Murillo R, Jeronimo J, Tsu V, Carvalho A, Gil CF, Sternberg C, Dueñas-Gonzalez A, Sgroi D, Cuello M, Fresco R, Reis RM, Masera G, Gabús R, Ribeiro R, Knust R, Ismael G, Rosenblatt E, Roth B, Villa L, Solares AL, Leon MX, Torres-Vigil I, Covarrubias-Gomez A, Hernández A, Bertolino M, Schwartsmann G, Santillana S, Esteva F, Fein L, Mano M, Gomez H, Hurlbert M, Durstine A and Azenha G: Planning cancer control in Latin America and the Caribbean. Lancet Oncol 14(5): 391-436, 2013.

4 Estimativa 2018: Incidência de Câncer no Brasil. Available from: http://www1.inca.gov.br/vigilancia/

5 Elmunzer BJ, Hayward RA, Schoenfeld PS, Saini SD, Deshpande A and Waljee AK: Effect of flexible sigmoidoscopybased screening on incidence and mortality of colorectal cancer: a systematic review and meta-analysis of randomized controlled trials. PLoS Med 9(12): e1001352, 2012.

6 Towler B, Irwig L, Glasziou P, Kewenter J, Weller D and Silagy C: A systematic review of the effects of screening for colorectal cancer using the faecal occult blood test, hemoccult. Bmj 317(7158): 559-565, 1998.

7 Ponugoti PL, Cummings OW and Rex DK: Risk of cancer in small and diminutive colorectal polyps. Dig Liver Dis 49(1): 3437, 2017.

8 Shussman $\mathrm{N}$ and Wexner SD: Colorectal polyps and polyposis syndromes. Gastroenterol Rep (Oxf) 2(1): 1-15, 2014.

9 Rex DK, Boland CR, Dominitz JA, Giardiello FM, Johnson DA, Kaltenbach T, Levin TR, Lieberman D and Robertson DJ: Colorectal cancer screening: Recommendations for physicians and patients from the U.S. Multi-Society Task Force on Colorectal Cancer. Gastrointest Endosc 86(1): 18-33, 2017.

10 Inadomi JM: Screening for Colorectal Neoplasia. N Engl J Med 376(2): 149-156, 2017.

11 Lee TJ, Clifford GM, Rajasekhar P, Rutter MD, Kometa S, Ritchie MC, Waddup G, Nylander D, McNally RJ and Rees CJ: High yield of colorectal neoplasia detected by colonoscopy following a positive faecal occult blood test in the NHS Bowel Cancer Screening Programme. J Med Screen 18(2): 82-86, 2011.

12 Toes-Zoutendijk E, van Leerdam ME, Dekker E, van Hees F, Penning C, Nagtegaal I, van der Meulen MP, van Vuuren AJ,
Kuipers EJ and Bonfrer JMG: Real-time monitoring of results during first year of Dutch colorectal cancer screening program and optimization by altering fecal immunochemical test cut-off levels. Gastroenterology 152(4): 767-775.e762, 2017.

13 Chiu HM, Ching JY, Wu KC, Rerknimitr R, Li J, Wu DC, Goh KL, Matsuda T, Kim HS and Leong R: A risk-scoring system combined with a fecal immunochemical test is effective in screening high-risk subjects for early colonoscopy to detect advanced colorectal neoplasms. Gastroenterology 150(3): 617-625.e613, 2016.

14 Kronborg O, Fenger C, Olsen J, Jorgensen OD and Sondergaard $\mathrm{O}$ : Randomised study of screening for colorectal cancer with faecal-occult-blood test. Lancet 348(9040): 1467-1471, 1996.

15 Mandel JS, Bond JH, Church TR, Snover DC, Bradley GM, Schuman LM and Ederer F: Reducing mortality from colorectal cancer by screening for fecal occult blood. Minnesota Colon Cancer Control Study. N Engl J Med 328(19): 1365-1371,1993.

16 Scholefield JH, Moss S, Sufi F, Mangham CM and Hardcastle JD: Effect of faecal occult blood screening on mortality from colorectal cancer: results from a randomised controlled trial. Gut 50(6): 840-844, 2002.

17 Jaffe RM, Kasten B, Young DS and MacLowry JD: Falsenegative stool occult blood tests caused by ingestion of ascorbic acid (vitamin C). Ann Intern Med 83(6): 824-826, 1975.

18 Adlercreutz H, Suovaniemi O, Partanen P and Suni J: Immunoassay for fecal human hemoglobin. In: vol. US4427769 patent: Labsystems OY, Helsinki, Finland, 1981.

19 Songster CL, Barrows GH and Jarrett DD: Immunochemical detection of fecal occult blood--the fecal smear punch-disc test: a new non-invasive screening test for colorectal cancer. Cancer 45(5 Suppl): 1099-1102, 1980.

20 Rabeneck L, Rumble RB, Thompson F, Mills M, Oleschuk C, Whibley A, Messersmith $\mathrm{H}$ and Lewis $\mathrm{N}$ : Fecal immunochemical tests compared with guaiac fecal occult blood tests for population-based colorectal cancer screening. Can J Gastroenterol 26(3): 131-147, 2012.

21 van Rossum LG, van Rijn AF, Laheij RJ, van Oijen MG, Fockens P, van Krieken HH, Verbeek AL, Jansen JB and Dekker E: Random comparison of guaiac and immunochemical fecal occult blood tests for colorectal cancer in a screening population. Gastroenterology 135(1): 82-90, 2008.

22 Lee JK, Liles EG, Bent S, Levin TR and Corley DA: Accuracy of fecal immunochemical tests for colorectal cancer: systematic review and meta-analysis. Ann Intern Med 160(3): 171-183, 2014.

23 Vasilyev S, Smirnova E, Popov D, Semenov A, Eklund C, Hendolin P, Paloheimo L and Syrjanen K: A New-generation fecal immunochemical test (FIT) is superior to quaiac-based test in detecting colorectal neoplasia among colonoscopy referral patients. Anticancer Res 35(5): 2873-2880, 2015.

24 The Paris endoscopic classification of superficial neoplastic lesions: esophagus, stomach, and colon: November 30 to December 1, 2002. Gastrointest Endosc 58(6 Suppl): S3-43, 2003.

25 Bosman FT, Carneiro F, Hruban RH and Theise ND: WHO Classification of Tumours of the Digestive System. Fourth Edition, World Health Organization, 2010.

26 Bibbins-Domingo K, Grossman DC, Curry SJ, Davidson KW, Epling JW Jr., Garcia FAR, Gillman MW, Harper DM, Kemper $\mathrm{AR}$ and Krist AH: Screening for colorectal cancer: US Preventive Services Task Force Recommendation Statement. JAMA 315(23): 2564-2575, 2016. 
27 Shapiro JA, Bobo JK, Church TR, Rex DK, Chovnick G, Thompson TD, Zauber AG, Lieberman D, Levin TR and Joseph DA: A comparison of fecal immunochemical and high-sensitivity guaiac tests for colorectal cancer screening. Am J Gastroenterol 112(11): 1728-1735, 2017.

28 Sieg A, Thoms C, Luthgens K, John MR and Schmidt-Gayk H: Detection of colorectal neoplasms by the highly sensitive hemoglobin-haptoglobin complex in feces. Int J Colorectal Dis 14(6): 267-271,1999.

29 Frommer DJ, Kapparis A and Brown MK: Improved screening for colorectal cancer by immunological detection of occult blood. Br Med J (Clin Res Ed) 296(6629): 1092-1094, 1988.

30 Hoepffner N, Shastri YM, Hanisch E, Rosch W, Mossner J, Caspary WF and Stein J: Comparative evaluation of a new bedside faecal occult blood test in a prospective multicentre study. Aliment Pharmacol Ther 23(1): 145-154, 2006.

31 Rozen P, Knaani J and Samuel Z: Comparative screening with a sensitive guaiac and specific immunochemical occult blood test in an endoscopic study. Cancer 89(1): 46-52, 2000.

32 Wong BC, Wong WM, Cheung KL, Tong TS, Rozen P, Young GP, Chu KW, Ho J, Law WL and Tung HM: A sensitive guaiac faecal occult blood test is less useful than an immunochemical test for colorectal cancer screening in a Chinese population. Aliment Pharmacol Ther 18(9): 941-946, 2003.
33 Whitlock EP, Lin JS, Liles E, Beil TL and Fu R: Screening for colorectal cancer: a targeted, updated systematic review for the U.S. Preventive Services Task Force. Ann Intern Med 149(9): 638-658, 2008

$34 \mathrm{http} / / / \mathrm{www} \cdot$ biohithealthcare.com/additional-information

35 Smith A, Young GP, Cole SR and Bampton P: Comparison of a brush-sampling fecal immunochemical test for hemoglobin with a sensitive guaiac-based fecal occult blood test in detection of colorectal neoplasia. Cancer 107(9): 2152-2159, 2006.

36 Parra-Blanco A, Gimeno-Garcia AZ, Quintero E, Nicolas D, Moreno SG, Jimenez A, Hernandez-Guerra M, Carrillo-Palau M, Eishi Y and Lopez-Bastida J: Diagnostic accuracy of immunochemical versus guaiac faecal occult blood tests for colorectal cancer screening. J Gastroenterol 45(7): 703-712, 2010.

Received November 8, 2018

Revised November 19, 2018

Accepted November 20, 2018 